\title{
A three dimensional hydrogen bonded organic framework assembled through antielectrostatic hydrogen bonds
}

\author{
Duncan A. Cullen, Michael G. Gardiner and Nicholas G. White* \\ Research School of Chemistry, The Australian National University, Canberra, ACT, Australia \\ www.nwhitegroup.com nicholas.white@anu.edu.au
}

Crystalline 3D hydrogen bonded frameworks are assembled in water from tetrahedral tetraamidinium cations and antielectrostatically hydrogen bonded bicarbonate dimers. The framework forms in water, and represents a clear demonstration of the potency of these anti-Coulombic hydrogen bonds. Gentle heating of the framework $\left(50^{\circ} \mathrm{C}\right)$ releases $\mathrm{CO}_{2}$ and water to give the neutral tetraamidine compound.

It would appear intuitive that anions repel one another due to Coulombic effects. However, pioneering computational studies by Weinhold suggested that such interactions may be favourable if the anions possess hydrogen bond donors, due to antielectrostatic hydrogen bonds (AEHBs) between the anions.' This study built upon a body of work that implicated such anion ". anion interactions in dihydrogenphosphate complexes, ${ }^{2}$ and culminated in a recent study by Flood that observed the $\mathrm{O}-\mathrm{H} \cdots \mathrm{O}$ hydrogen bond of a $\mathrm{HSO}_{4}{ }^{-} \cdots \mathrm{HSO}_{4}^{-}$pair stabilised within macrocyclic receptors using 'H NMR spectroscopy. ${ }^{3}$ Subsequently, a handful of other reports have provided clear evidence that these type of anion " anion hydrogen bonds persist in solution. ${ }^{4}$

In contrast to the relative paucity of evidence for the existence of $\mathrm{AEHBs}$ in solution, these interactions are quite well-documented in the solid state. In part this is probably due to additional nearby ionic interactions present in crystal structures that can stabilise the Coulombic repulsion between the anions. A recent survey of the Cambridge Structural Database ${ }^{5}$ (CSD) found that $A E H B$ interactions are relatively common, and occur for a wide variety of anions. Notably, over half of the structurally characterized bicarbonate anions in the CSD occur as AEHB $\mathrm{HCO}_{3}{ }^{-} \cdot \mathrm{HCO}_{3}{ }^{-}$dimers. ${ }^{6}$

Given that historically these interactions were often overlooked or believed to be very weak, it is unsurprising that they have not received much attention in the context of crystal engineering. Nevertheless, a few studies have been conducted. Notably, Mak's group have demonstrated that the interactions between guanidinium cations and AEHB bicarbonate dimers can be used to form discrete rosette structures, which are linked into anionic 2D sheets by other carboxylate anions (with tetrabutylammonium cations balancing the charge). ${ }^{7}$ Recently, Custelcean has shown that bisiminoguanidinium cations form insoluble crystalline 2D sheets with hydrated bicarbonate dimers, and that this crystallisation process can be used to remove $\mathrm{CO}_{2}$ from simulated flue gas. ${ }^{8}$

We were interested to see whether $A E H B$ interactions could be used to link cationic hydrogen bond donors into 3D hydrogen bonded organic frameworks. ${ }^{9}$ We decided to use the bicarbonate dimer as our AEHB motif due to its structural similarity to carboxylate anions, which we have previously shown can be assembled into predictable hydrogen bonded materials with polyamidinium cations, such as $\mathrm{I}^{4+}(\mathrm{Fig} \mathrm{I}) .^{10}$ In this work, we report the synthesis of $3 D$ frameworks, which are assembled from AEHB bicarbonate dimers and tetraamidinium cations. Not only can AEHB dimers be used to assemble a $3 D$ crystalline material, this material forms in water." We believe this is the first example of a three-dimensional framework assembled using antielectrostatic hydrogen bonds.

Adding an aqueous solution of $\mathrm{NaHCO}_{3}$ to the tetraamidinium $\mathbf{I} \mathbf{C l}_{4}$ in water and leaving the resulting solution to stand resulted in the precipitation of single crystals. Analysis by $\mathrm{X}$-ray crystallography showed the product was the framework I ( $\left.\mathbf{H C O}_{3}\right)_{4} \mathrm{nH}_{2} \mathrm{O}$, $†$ which consists of an overall cationic 3D framework consisting of a $\mathrm{I}: \mathrm{I}$ ratio of $\mathrm{I}^{4+}$ and a $2^{-}$bicarbonate dimer (Fig. 2).

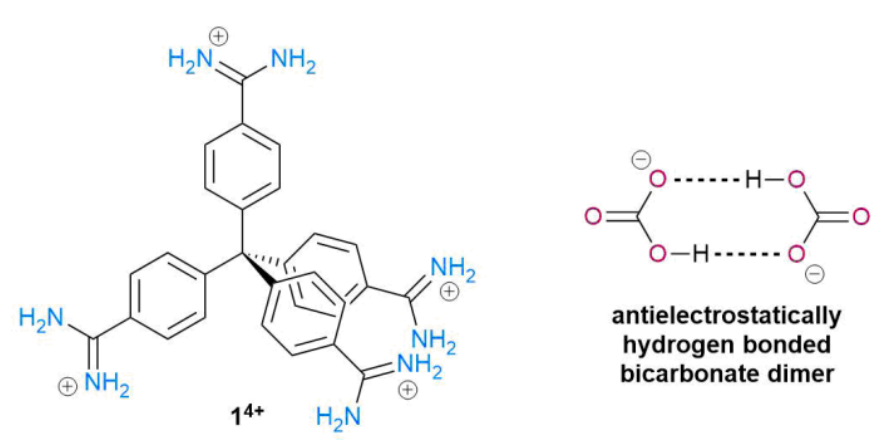

Fig. I Structure of tetraamidinium building block $\mathrm{I}^{4+}$ and AEHB bicarbonate dimer. 
This cationic framework contains channels, which comprise $25 \%$ of the crystal volume, and are filled with one additional bicarbonate dimer per amidinium cation, as well as water solvent molecules, with both the AEHB dimer and waters disordered about a four-fold screw axis (see ESI for full details of X-ray crystallography).

The diamondoid framework is assembled by bicarbonate dimer linkers, with short $\mathrm{O}-\mathrm{H} \cdots \mathrm{O}$ hydrogen bonds between the anions $[\mathrm{H} \cdots \mathrm{O}=1.77 \AA$, $65 \%$ of the sum of the van der Waals radii ${ }^{12}$ of $\mathrm{H}$ and $\left.\mathrm{O}\right] .{ }^{13}$ The $\mathrm{O} \cdots \mathrm{O}$ distances in the dimer are 2.57I(8) $\AA$, slightly shorter than the mean $O \cdots O$ distance in a recent CSD survey of these interactions $(2.606 \AA) .^{6}$ Interestingly, the bicarbonate dimers in the cavities have slightly longer $\mathrm{O} \cdots \mathrm{O}$ distances $[2.640(9) \AA]$. Hydrogen bonds between the amidinium groups and anion are also short $[\mathrm{H} \cdots \mathrm{O}=1.95,1.97 \AA$; $72,73 \%$ of the sum of the van der Waals ${ }^{12}$ radii of $\mathrm{H}$ and O]. The overall structure is assembled through four of these H-bonded diamondoid frameworks, which interpenetrate (Figure SII).

Interestingly, the speed of framework formation was dependent on the number of equivalents of $\mathrm{HCO}_{3}{ }^{-}$anion present. Using 50 equivalent of $\mathrm{NaHCO}_{3}$ for each molecule of $\mathbf{I}^{4+}$ (i.e. 12.5 equivalents per amidinium) gave single crystals within two days, while if a $100: 1$ ratio of $\mathrm{NaHCO}_{3}: \mathrm{I}^{4+}$ was used, crystals were formed within a few hours. Using a 4:I $\mathrm{NaHCO}_{3}: \mathrm{I}^{4+}$ ratio, i.e. the "correct" stoichiometric ratio, did not give crystals even after several months. We suggest that the hydrogen bonding interaction between the amidinium and bicarbonate groups is relatively weak in water, and so there is relatively little association in solution. Using an excess of bicarbonate drives this equilibrium towards association, and thus crystallisation.
To gain insight into the selectivity of the amidinium 'bicarbonate dimer interaction, we added large excesses of various other anions to a solution of I $4 \mathrm{Cl}$ in water ( 25 equivalents per amidinium site, $\mathrm{HCO}_{3}{ }^{-}$ caused crystallisation within hours under these conditions). We tested $\mathrm{Cl}^{-}, \mathrm{I}^{-}, \mathrm{NO}_{3}^{-}, \mathrm{H}_{2} \mathrm{PO}_{4}^{-}, \mathrm{HSO}_{4}^{-}$, $\mathrm{SO}_{4}{ }^{2-}$, but in no case did we observe any precipitate. It is remarkable that the bicarbonate dimer, composed of monovalent anions that must interact in an antiCoulombic fashion is able to form a framework, while $\mathrm{SO}_{4}{ }^{2-}$ does not. ${ }^{14}$

The framework could be prepared "in bulk" in 63\% yield. Despite being assembled by presumably relatively weak antielectrostatic hydrogen bonds, the structure shows good stability, and the crystal lattice remains stable upon drying (as determined by powder X-ray diffraction studies, see ESI). Further characterisation by elemental analyses, IR spectroscopy, NMR spectroscopy of aciddigested material, and thermogravimetric analysis were all consistent with the bulk framework having the same structure as the singly-crystalline material.

While the crystalline framework is stable at room temperature, it can be readily converted to the tetraamidine 2 by heating. TGA indicates that this process begins at about $75{ }^{\circ} \mathrm{C}$ in the solid state. On a preparative scale, heating a sample of $\mathrm{I}\left(\mathrm{HCO}_{3}\right)_{4}$ at $95{ }^{\circ} \mathrm{C}$ for two hours converts the framework to the novel tetraamidine 2 in quantitative yield and good purity ( 95\%, see ESI). Remarkably, when the framework is suspended in DMSO this transition occurs at even lower temperatures than in the solid state. Indeed heating $\mathbf{I}\left(\mathbf{H C O}_{3}\right)_{4}$ at $50{ }^{\circ} \mathrm{C}$ in DMSO gives complete conversion to $\mathbf{2}$ in > $95 \%$ purity.
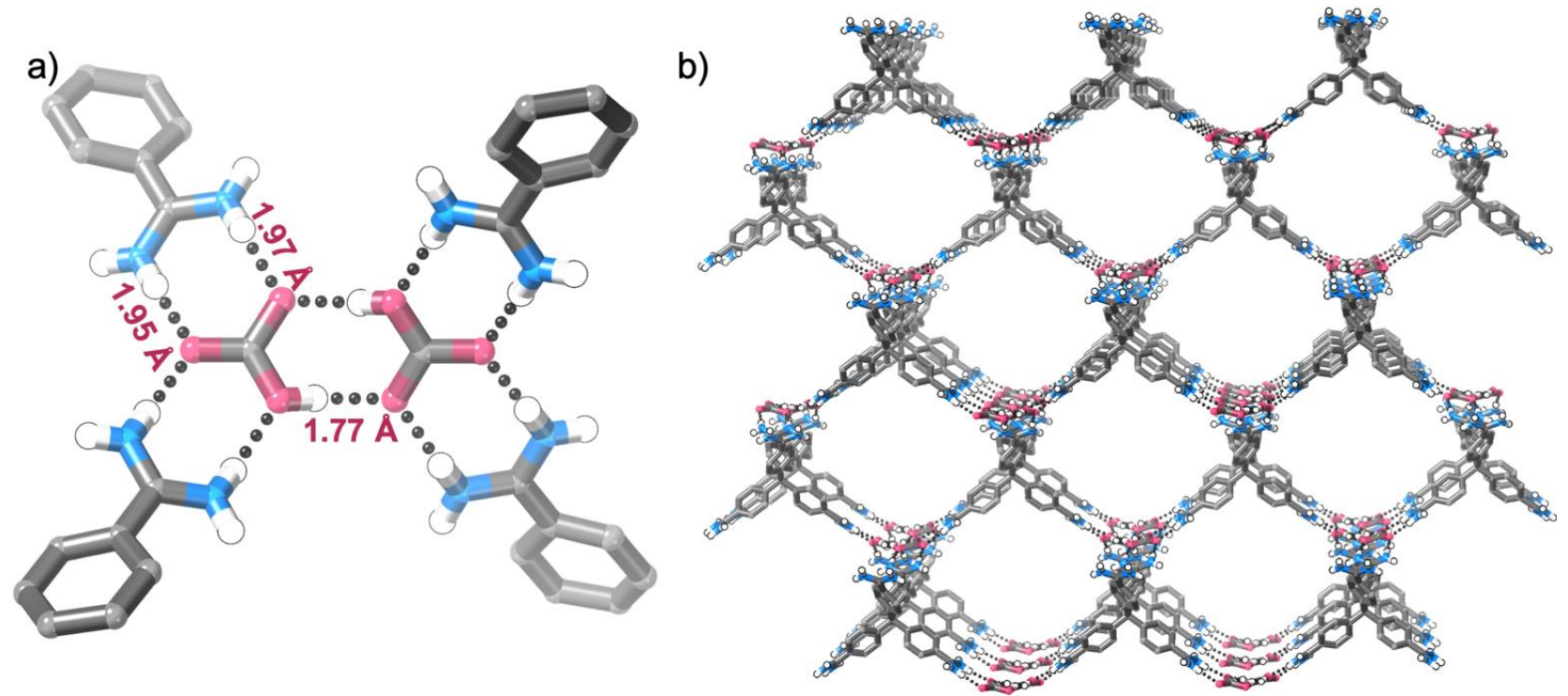

Fig. 2 Views of structure of $\mathrm{AEHB}$ framework $\mathrm{I}\left(\mathbf{H C O}_{3}\right)_{4}$ : a) view of hydrogen bonding interactions showing unique $\mathrm{H} \cdots \mathrm{O}$ distances (a fourfold screw axis is present located between the two $\mathrm{HCO}_{3}^{-}$anions); b) view of one of the diamondoid nets. $\mathrm{C}-\mathrm{H}$ hydrogen atoms, water molecules, and bicarbonate dimers in pores are omitted for clarity. 
We attribute this transformation to a loss of four molecules each of carbon dioxide and water, in a similar manner to that observed by Custelcean for guanidinium carbonate $^{15}$ and guanidinium bicarbonate ${ }^{8}$ systems (Scheme I). Interestingly, we have been unable to prepare 2 directly from tetraamidinium $\mathrm{I}^{4+}$ using conventional techniques due to its tendency to hydrolyse in the presence of aqueous base. Heating $\mathbf{I}\left(\mathbf{H C O}_{3}\right)$ at higher temperatures gives the tetranitrile species $\mathbf{3}$, presumably through loss of four molecules of ammonia from the initially-formed amidine.

As well as characterising the new tetraamidine 2 by ' $\mathrm{H}$ and ${ }^{13} \mathrm{C}$ NMR spectroscopy, IR spectroscopy and high resolution mass spectrometry, we were able to obtain single crystals by vapour diffusion of diethyl ether into an acetone/methanol solution of the compound. X-ray crystallography reveals that the compound crystallises in a tetragonal space group with one quarter of the molecule and one methanol solvent in the asymmetric unit. Short hydrogen bonds are present between amidine $\mathrm{N}-\mathrm{H}$ groups and the methanol solvent's oxygen atom, and then between the methanol $\mathrm{O}-\mathrm{H}$ group and an amidine $\mathrm{N}$ atom (Fig 3) and these facilitate the formation of a 3D network. We note that amidine functional groups contain $\mathrm{H}$-bond donors and acceptors, so it may be possible to prepare porous hydrogen bonded organic frameworks (HOFs) from 2 or similar polyamidine molecules.

In this work, we have shown that antielectrostatic hydrogen bonds can be used to prepare crystalline 3D framework materials. Remarkably these materials can be prepared in water, demonstrating the strength of these interactions. We have also shown that the amidinium motif can behave similarly to the guanidinium group in that amidinium bicarbonate salts can readily release $\mathrm{CO}_{2}$ and $\mathrm{H}_{2} \mathrm{O}$ upon heating to give the neutral amidine compounds. This has allowed us to prepare the tetraamidine $\mathbf{2}$ in good yield, which we have been unable to access using other synthetic routes. We suggest that this and other polyamidines may be of interest both from crystal engineering and carbon sequestration perspectives.

This work was funded by the Australian Research Council (Discovery Early Career Research Award, DEI70100200). We thank Dr Leesa Smith and Prof. Michelle Coote for assistance with thermogravimetric analysis.

There are no conflicts of interest to declare.

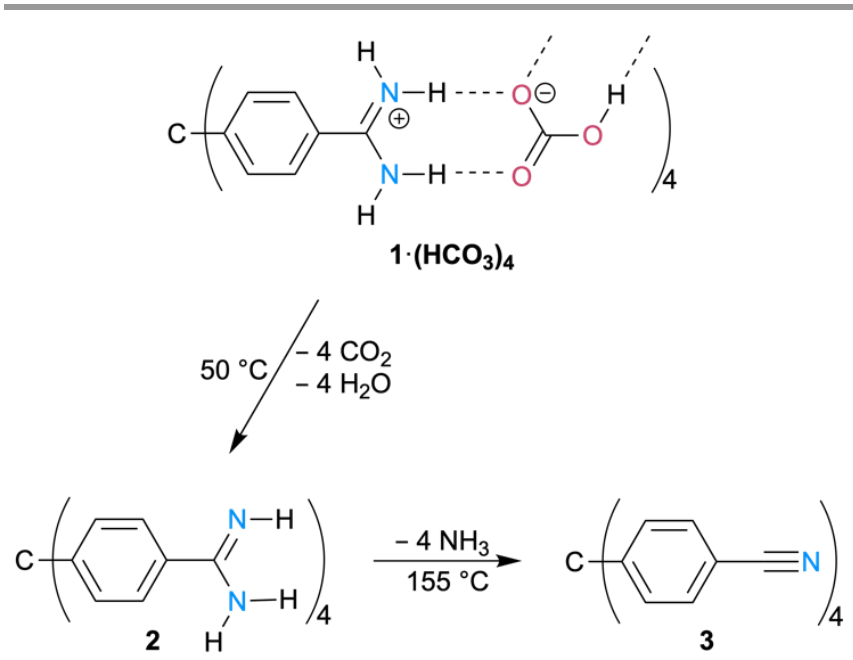

Scheme I Proposed thermal decomposition of $\mathbf{I}\left(\mathrm{HCO}_{3}\right)_{4}$ to tetraamidine 2 and tetranitrile 3 . The conversion of $\mathrm{I}\left(\mathrm{HCO}_{3}\right)_{4}$ to 2 occurs at $50^{\circ} \mathrm{C}$ in DMSO, but TGA occurs that it occurs at about $75^{\circ} \mathrm{C}$ in the solid state.
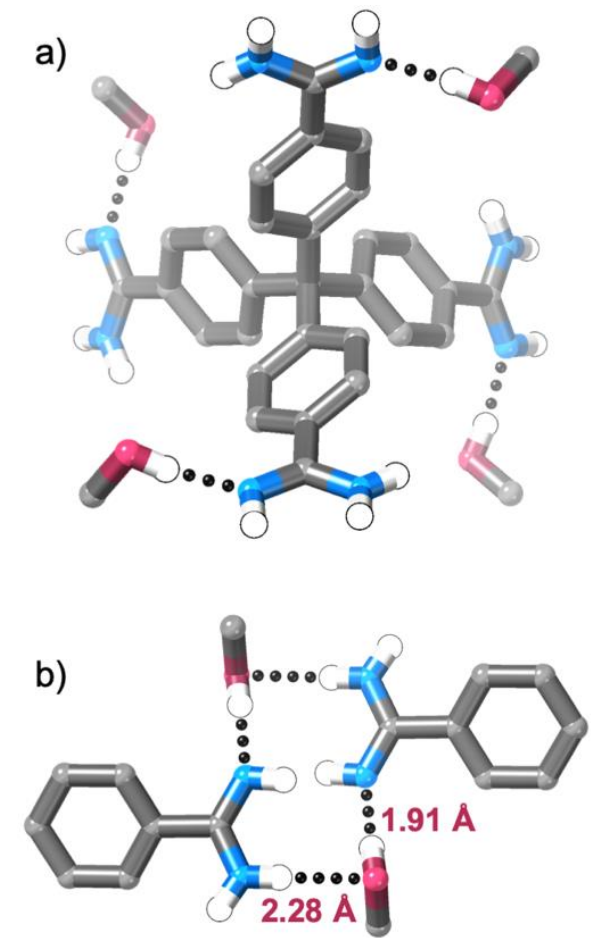

Fig. 3 Views of structure of $2 \cdot\left(\mathrm{CH}_{3} \mathrm{OH}\right)_{4}$ : a) view of one molecule; b) view of the intramolecular H-bonding showing crystallographically unique $\mathrm{H} \cdots \mathrm{O}$ and $\mathrm{H} \cdots \mathrm{N}$ distances. $\mathrm{C}-\mathrm{H}$ hydrogen atoms are omitted for clarity. 


\section{Notes and references}

$\dagger$ In the crystal structure, $n=3$; after air-drying, elemental analysis and thermogravimetric analysis indicate that $n=$ 2.5 .

I F. Weinhold and R. A. Klein, Angew. Chem., Int. Ed., 20I4, 53, II2I4-II2I7.

2 a) L. S. Flatt, V. Lynch and E. V. Anslyn, Tetrahedron Lett., 1992, 33, 2785-2788; b) S. Valiyaveettil, J. F. J. Engbersen, W. Verboom and D. N. Reinhoudt, Angew. Chem., Int. Ed., 1993, 32, 900-90I; c) D. M. Rudkevich, W. Verboom, Z. Brzozka, M. J. Palys, W. P. R. V. Stauthamer, G. J. van Hummel, S. M. Franken, S. Harkema, J. F. J. Engbersen and D. N. Reinhoudt, J. Am. Chem. Soc., I 994, II 6, 434I-435I; d) J. Cai, B. P. Hay, N. J. Young, X. Yang and J. L. Sessler, Chem. Sci., 20I3, 4, I560-I567; e) N. Bregović, N. Cindro, L. Frkanec, K. Užarević and V. Tomišić, Chem. Eur. J., 20I4, 20, I 5863I587I; f) Q. He, P. Tu and J. L. Sessler, Chem, 20I8, 4, 46-93.

3 E. M. Fatila, E. B. Twum, A. Sengupta, M. Pink, J. A. Karty, K. Raghavachari and A. H. Flood, Angew. Chem., Int. Ed., $2016,55,14057-14062$.

4 a) E. M. Fatila, E. B. Twum, J. A. Karty and A. H. Flood, Chem. Eur. J., 2017, 23, 10652-I0662; b) W. Zhao, B. Qiao, C.-H. Chen and A. H. Flood, Angew. Chem., Int. Ed., 2017, 56, 13083-13087; c) D. Mungalpara, A. Valkonen, K. Rissanen and S. Kubik, Chem. Sci., 2017, 8, 6005-60I3; d) J. S. McNally, X. P. Wang, C. Hoffmann and A. D. Wilson, Chem. Commun., 2017, 53, 1093410937; e) R. Prohens, A. Portell, M. Font-Bardia, A. Bauzá and A. Frontera, Chem. Commun., 2018, 54, I84II844; f) $H$. Valkenier, O. Akrawi, P. Jurček, K. Sleziaková, T. Lízal, K. Bartik and V. Šindelář, Chem, 2019, 5, 429-444; g) W. Zhao, B. Qiao, J. Tropp, M. Pink, J. D. Azoulay and A. H. Flood, J. Am. Chem. Soc., 2019, I 4 I, 4980-4989.

5 C. R. Groom, I. J. Bruno, M. P. Lightfoot and S. C. Ward, Acta Crystallogr., 20 I6, B72, I7I-I79.

6 N. G. White, CrystEngComm, 2019, 2 I, 4855-4888.

7 a) T. C. W. Mak and F. Xue, J. Am. Chem. Soc., 2000, I 22, 9860-986I; b) J. Han, C.-W. Yau, C. W. Chan and T. C. W. Mak, Cryst. Growth Des., 20I 2, I 2, 4457-4465.

8 N. J. Williams, C. A. Seipp, F. M. Brethomé, Y.-Z. Ma, A S. Ivanov, V. S. Bryantsev, M. K. Kidder, H. J. Martin, E. Holguin, K. A. Garrabrant and R. Custelcean, Chem, $2019,5,719-730$.

9 a) R.-B. Lin, Y. He, P. Li, H. Wang, W. Zhou and B. Chen, Chem. Soc. Rev., 2019, 48, I362-I389; b) N. G. White, Dalton Trans., 20I9, 48, 7062-7068; c) I. Hisaki, C. Xin, K. Takahashi and T. Nakamura, Angew. Chem., Int. Ed., 2019, 58, III60-11170.

10 a) M. Morshedi, M. Thomas, A. Tarzia, C. J. Doonan and N. G. White, Chem. Sci., 2017, 8, 3019-3025; b) S. A. Boer, M. Morshedi, A. Tarzia, C. J. Doonan and N. G. White, Chem. Eur. J., 2019, 25, 10006-100I2.

II See Ref. 4d for an example of bicarbonate dimers forming in an aqueous environment in a microstructured system formed from tertiary ammonium amphiphiles.

I2 S. Alvarez, Dalton Trans., 20I3, 42, 86I7-8636.

I 3 Note that SCXRD studies are known to underestimate the length of $\mathrm{R}-\mathrm{H}$ bonds involving hydrogen atoms, meaning the real $\mathrm{H} \cdots \mathrm{O}$ distances are likely shorter than reported: a) R. Taylor and O. Kennard, Acc. Chem. Res. 1984, I7, 320-326. Wilson has reported a neutron diffraction study of the bicarbonate dimer, which found that the $\mathrm{O}-\mathrm{H}$ bond lengths were $\mathrm{I} .0 \mathrm{I} \AA$, and the $\mathrm{O} \cdots \mathrm{H}$ distances were I.60 $\AA$, see Ref. 4d.

I4 It should be noted that organic dicarboxylates have been shown to cause $\mathbf{I}^{4+}$ to crystallise from water, see Ref. 10. Oxalate also causes the formation of a crystalline framework: M. Morshedi and N. G. White, CrystEngComm, 2017, 19, 2367-237I.

I5 C. A. Seipp, N. J. Williams, M. K. Kidder and R. Custelcean, Angew. Chem., Int. Ed., 20 I7, 56, I042-I 045. 